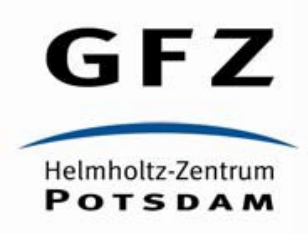

Originally published as:

Liang, Q., Chen, C., Kaban, M. K., Thomas, M. (2019): Upper-mantle density structure in the Philippine Sea and adjacent region and its relation to tectonics. - Geophysical Journal International, 219, 2, pp. 945-957

DOI: http://doi.org/10.1093/gji/ggz335

This article has been accepted for publication in Geophysical Journal International @The Author(s) 2019. Published by Oxford University Press on behalf of the Royal Astronomical Society. All rights reserved. 


\title{
Upper-mantle density structure in the Philippine Sea and adjacent region and its relation to tectonics
}

\author{
Qing Liang, ${ }^{1,2}$ Chao Chen, ${ }^{1,2}$ Mikhail K. Kaban ${ }^{2,4}$ and Maik Thomas ${ }^{2,3}$ \\ ${ }^{1}$ Institute of Geophysics and Geomatics, China University of Geosciences, Wuhan 430074, P. R. China. E-mail:qliang@cug.edu.cn; chenchao@cug.edu.cn \\ ${ }^{2}$ Helmholtz Centre Potsdam, GFZ German Research Centre for Geosciences, Potsdam 14473, Germany \\ ${ }^{3}$ Institute of Meteorology, Freie Universität Berlin, Berlin 12165, Germany \\ ${ }^{4}$ Schmidt Institute of Physics of the Earth RAS, Moscow 123242, Russia
}

Accepted 2019 July 20. Received 2019 June 14; in original form 2019 February 27

\begin{abstract}
SUMMAR Y
The evolution of the Philippine Sea Plate (PSP) since Jurassic is one of the key issues in the dynamics of lithosphere and mantle. The related studies benefited mostly from seismic tomography which provides velocity structures in the upper mantle. However, the upper-mantle structure is not well resolved compared to the continental areas due to the lack of seismic data in the Philippine Sea. We employ a 3-D gravity inversion constrained by an initial model based on the $S$-wave tomography (SL2013sv; Schaeffer \& Lebedev 2013) to image the density structure of the upper mantle of the PSP and adjacent region. The resulting model shows a three-layer pattern of vertical high-low-high density variation in the upper mantle under the PSP. The thin high-density layer evidences for strong oceanic lithosphere in the West Philippine Sea. The relatively low dense mantle located below the PSP possibly originates from the asthenosphere. The PSP differs from the Pacific and the Indian-Australian plates in the whole depth range, while its structure is similar to the eastern Eurasian and Sunda plates. In the depth range, 200-300 km, the relative high-density zone beneath PSP extends to the Sunda Plate and to the eastern Eurasian Plate. We further estimated the conversion factor of our density model and the velocity model (SL2013sv; Schaeffer \& Lebedev 2013) in order to locate the changes of compositional effects in the upper mantle. The negative conversion factor indicates that the compositional changes primarily affect the density anomalies beneath the PSP. We, therefore, describe the layered density structures as 'sandwich' pattern, which is unique and different from adjacent regions.
\end{abstract}

Key words: Gravity anomalies and Earth structure; Joint inversion; Dynamics of lithosphere and mantle.

\section{INTRODUCTION}

The Philippine Sea Plate (PSP) is located west of the Pacific Plate (PP), connecting it to eastern Eurasia. It is surrounded by trenches and subduction zones (Fig. 1a). The PP subduction beneath the Eurasian Plate (EP) is one of the most significant factors affecting the present day structure and evolution history of the upper mantle of the PSP and adjacent region since the Jurassic. Recent studies presented new features of the subduction along its eastern and western margins. Zhao et al. (2017) employed seismic tomography in combination with the deep large earthquake, Bonin 2015, to prove that the subducting slab of the PP is teared at $\sim 28^{\circ} \mathrm{N}$ on the eastern margin of the PSP. The northern segment of the subducted slab is stagnated in the transition zone, while the southern one nearly vertically penetrates into the lower mantle. These results may stimulate reconsidering the origin of earthquakes, volcanoes and backarc spreading along the Mariana trench. Yu et al. (2017) estimated uppermost mantle temperatures and thermal thicknesses of the lithosphere for southeastern Asia by converting a new $S$ wave velocity model (Tang \& Zheng 2013), whose resolution was locally improved. The thermal structure implies a uniform hightemperature layer at the depths $100-180 \mathrm{~km}$ under the EP and the western PSP. This might suggest that the westward penetration of the PSP slab is insignificant and the subducted slab does not penetrate westwards into the deep asthenosphere.

Several tomography studies focusing on the crust and the upper mantle in the study area have been performed in the last decades. These studies mainly aimed to define morphology, geometry and physical properties of the subducting PP and adjacent collision zones (e.g. Miller et al. 2004; Huang \& Zhao 2006; Isse et al. 2009; Hall \& Spakman 2015; Porritt et al. 2016; Wu et al. 2016; Zhao et al. 2017). $P$ - and $S$-wave velocity models demonstrate extreme heterogeneity of the crust and the upper mantle in the study region (Shito et al. 2015). From the western to the eastern 

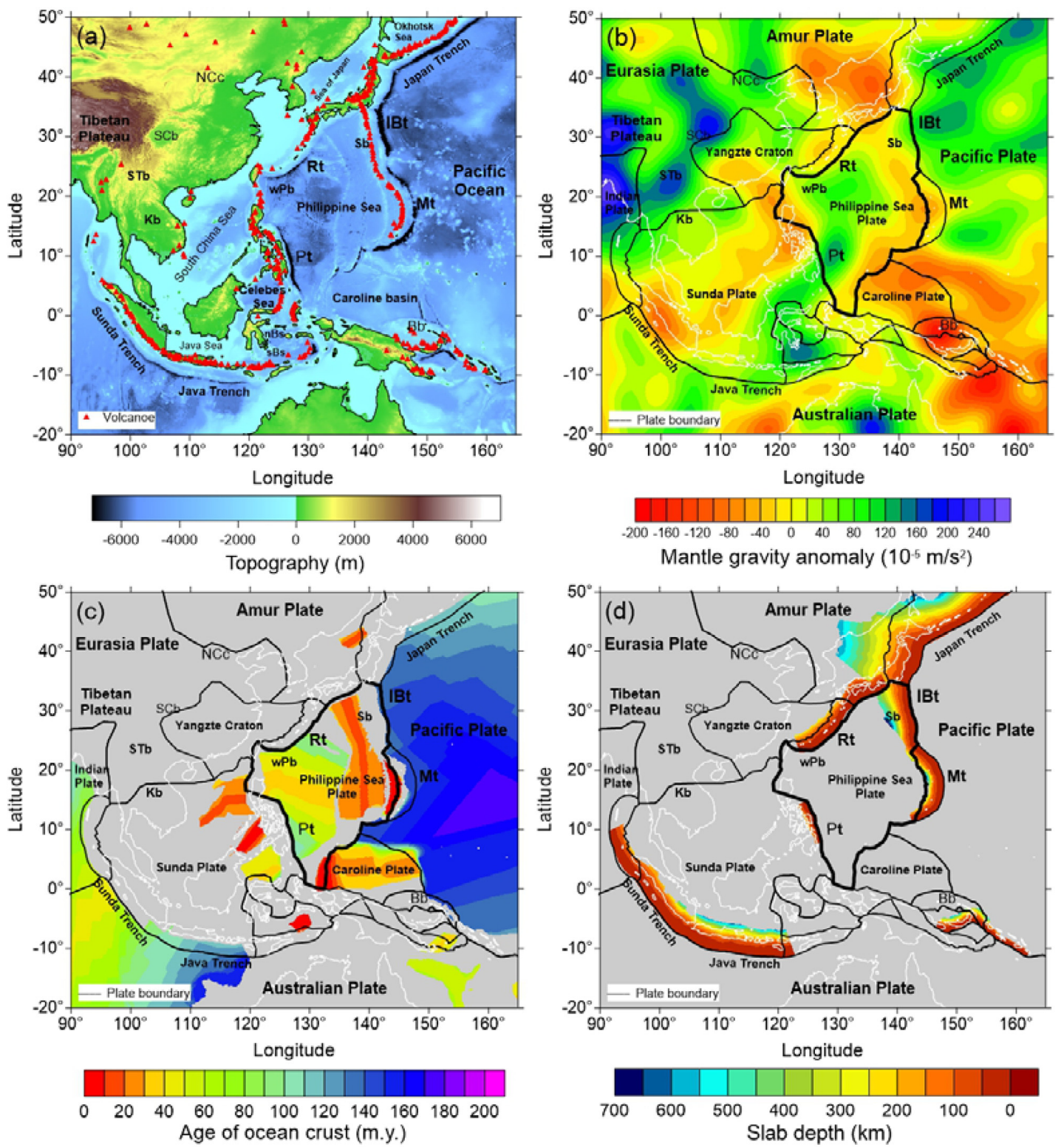

Figure 1. (a) Topography of the Philippine Sea and surrounding regions. (b) Residual mantle gravity anomaly (Kaban et al. 2016) after removing the effects of topography/bathymetry, sediments, crustal density variation and the Moho relief from the free air gravity anomaly (EIGEN-6c4 model, Förste et al. 2014). (c) Age of the ocean crust (Müller et al. 2008) and principal tectonic boundaries. (d) Slab depth (Hayes et al. 2012). The black solid lines represent global tectonic plates based on PB2002 (Bird 2003). The red triangles denote Holocene volcanoes from the Global Volcanism Program. Main tectonic units are labelled: Bb, Bismarck Basin; nBs, North Banda Sea; sBs, South Banda Sea; SCb, Sichuan basin; IBt, Izu-Bonin Trench; Kb, Khorat Basin; Mt, Mariana Trench; NCc, North China Craton; Sb, Shikoku Basin; STb, Shan-Thai Block; wPb, West Philippine Basin; Rt, Ryukyu Trench; Pt, Philippine Trench.

margins of the PSP, high seismic velocity anomalies reveal the location of subduction zones (e.g. Huang \& Zhao 2006; Zhao et al. 2017). However, beneath the Ryukyu-Philippine (RP) trench and the Izu-Bonin-Mariana (IBM) trench system, the evolution of the subduction zones during the periods of the PSP forming and moving northwestwards is still under debate (Deschamps \& Lallemand 2002). Due to the lack of seismic data in the Philippine Sea, the upper-mantle structure is not well resolved compared to the adjoining continental areas. Therefore, other parameters, such as density, are required to define composition and thermal structure of the lithosphere and asthenosphere. The gravity field may provide higher horizontal resolution of density variation that can help to identify different compositional domains in the lithosphere (e.g. Root et al. 2017).

Density of the upper mantle depends on temperature and composition, but in a different way than seismic velocities. Thus, density anomalies do not necessarily correlate with velocity variations (e.g. Anderson \& Bass 1984, Kaban et al. 2003). Density variations in the upper mantle represent one of the main factors controlling crustal movements and lithosphere dynamics. The pulling force of a dense subducting slab is widely accepted as one of the major driving forces in plate tectonics. Niu et al. (2003) suggested that the existence of a lateral compositional density contrast within the lithosphere may result in initiation of subduction. On the other hand, high-density 
material in the lower lithosphere due to low temperatures or compositional anomalies may lead to detachment of lithosphere blocks (Kay \& Kay 1993; Houseman \& Molnar 1997; Wang \& Currie 2015).

Triggered by recent satellite missions, in particular GRACE and GOCE, gravity data have become an important tool for investigating the Earth's density structure. Approaches based on integration of gravity and seismic data have been broadly applied to delineate the upper-mantle density structure (e.g. Brandmayr et al. 2011; Mooney \& Kaban 2010; Kaban et al. 2003, Chaves \& Ussami 2013; Kaban et al. 2014b, 2016). In this study, we attempt to invert mantle gravity anomalies (Fig. 1b) refined from the effect of the crust and deep mantle (Kaban et al. 2016), using the 3-D inversion algorithm (Liang et al. 2014) to investigate the upper-mantle density distribution beneath the Philippine Sea and surroundings.

\section{METHOD}

\subsection{Mantle gravity anomaly}

The mantle gravity anomalies (Fig. 1b), which are employed in this study, have been calculated by Kaban et al. (2016) after removing the effects of the crust and deep mantle from the initial gravity field (EIGEN-6c4; Förste et al. 2014). Gravity anomalies induced by density heterogeneity of the sedimentary layer, crystalline crust and of the Moho variations have been computed relative to a 1-D reference model (Table 1; Kaban et al. 2016), which consists of two crustal layers $\left(0-15 \mathrm{~km}, 2.7 \mathrm{~g} \mathrm{~cm}^{-3}\right.$ and $\left.15-40 \mathrm{~km}, 2.94 \mathrm{~g} \mathrm{~cm}^{-3}\right)$ underlain by the upper mantle with the density $3.357 \mathrm{~g} \mathrm{~cm}^{-3}$ in the top. Although this is a continental reference model, it is balanced in an isostatic sense with the oceanic crust-mantle structure, which corresponds to the $180 \mathrm{Ma}$ old oceanic lithosphere according to the cooling-plate model (Kaban \& Schwintzer 2001). Therefore, the total gravity effect of all crustal layers down to the Moho will be the same when employing both reference models (oceanic and continental). The effects of the crust are calculated using the crustal model (Stolk et al. 2013), which is based on a compilation of nearly all seismic determinations of crustal parameters. For estimation of the deep mantle effects, the tomography model S40RTS (Ritsema et al. 2011) has been employed in Petrunin et al. (2013) and Kaban et al. (2014a). These calculations require a whole mantle model, while the model SL2013sv gives only upper-mantle velocities. However, the choice of the global model is insignificant since the study area is relatively small and the global effects represent just linear trends, which do not affect the solution. After removing these effects from the observed field, the residual mantle gravity anomalies were calculated (Kaban et al. 2016).

Based on recent global dynamic models of the mantle (Kaban \& Trubitsyn 2012; Petrunin et al. 2013; Kaban et al. 2014a), the effect of deep density heterogeneity below $325 \mathrm{~km}$, which is not considered in this study, has been also removed from the gravity field (Kaban et al. 2016). The obtained upper-mantle gravity anomalies are shown in Fig. 1(b). One of the main features of this field is the extended minima connected to the plate collision zones, such as the IBM trenches, the RP trenches, the part of the Sunda trench and broad area of the convergent zone between the PP and the Australian Plate (AP). Relatively high mantle gravity anomalies appear in the central part of the PSP, extending to the Celebes and Banda Sea. Relative gravity maxima also characterize major areas of the PP, the EP and the AP in the study region.

\subsection{Algorithm and parameters of the gravity inversion}

The 3-D inversion algorithm of Liang et al. (2014) was used in this study. This method accounts for sphericity of the Earth, therefore it is applicable for large regions. 3-D gravity inversions are often performed in the Cartesian coordinate system while the surface is approximated as a plane. Since our study area covers $80^{\circ} \mathrm{E}-175^{\circ} \mathrm{E}$ in longitude and $30^{\circ} \mathrm{S}-60^{\circ} \mathrm{N}$ in latitude directions, the inversion should be certainly performed for the spherical Earth.

Since the resolution of the gravity anomalies is $1^{\circ} \times 1^{\circ}$, the density model is also represented on the same $1^{\circ} \times 1^{\circ}$ horizontal grid with a $50-\mathrm{km}$ step in depth. The thickness of the top tesseroid layer varies depending on the Moho depth.

For the inversion of the gravity data, constraining information derived from geological and geophysical data is necessary to restrict non-uniqueness and instability of the inversion. We follow the proposal of Li \& Oldenburg (1998) and select a density model, which is based on seismic tomography (Shaeffer \& Lebedev 2013), as an initial one. The 3-D initial model works as a constraint for the result of the inversion. Therefore, we define the objective function $\Phi$ as the following:

$\Phi=\Phi_{d}+\mu \Phi_{\rho}$,

where $\Phi_{d}$ is the data misfit and $\Phi_{\rho}$ denotes the model objective function, and $\mu$ is the balance factor also called as the regularization parameter that determines the trade-off between the two objective functions. The objective functions $\Phi_{d}$ and $\Phi_{\rho}$ can be expressed as a matrix, that is,

$\Phi_{d}=\|\mathbf{K} \rho-\mathbf{g}\|^{2}, \Phi_{\rho}=\mid \mathbf{W}_{\rho}\left(\rho-\rho_{\text {ini }}\right) \|^{2}$,

where $\mathbf{K}$ is the kernel matrix or the integral operator for converting density into the gravity field, $\mathbf{g}$ is the mantle gravity anomaly; $\rho$ and $\rho_{\text {ini }}$ represent the pending density and initial density vectors, respectively. $\mathbf{W}_{\rho}$ is one of the important parameters in the model objective function, which is defined as a weighting matrix in spherical coordinates (Liang et al. 2014).

The method has been tested on numerical models (Figs 2 and 3) to analyse resolution of the inversion method and the effect of uncertainties in the initial density structure, which is based on seismic tomography. These tests demonstrated that the shape of pre-defined density structures including lateral and vertical variations is reproduced in the inversion, although the density anomalies might be reduced due to damping (Fig. 4). The initial model provides basic constraints on the vertical structure for the ill-posed gravity inversion. However, the inversion significantly improves lateral resolution as demonstrated in Figs 2 and 4(e) and (f), for example, by revealing a high-density block of about $5^{\circ}(\sim 550 \mathrm{~km})$. In contrast, the unconstrained inversion of the gravity field does not resolve vertical density structure with the same block smeared to about $1100 \mathrm{~km}$ (Figs 4g and h). Furthermore, in the numerical test the radial resolution is also improved in the final model by revealing a $100-\mathrm{km}$ thick layer (Figs 4c and d), although the initial model is vertically uniform and does not include this layer.

\subsection{Initial 3-D density model}

In this study, the initial density model was derived from the velocity perturbations of the tomography model SL2013sv (Fig. 5) of Schaeffer \& Lebedev (2013). $S$-wave velocities were transformed into temperatures, and then to density perturbations using a mineralphysics approach as described in Tesauro et al. (2014). The initial temperatures and densities in this study are the same as in Kaban 
Table 1. 1-D reference density model of the crustal and upper mantle above $300 \mathrm{~km}$.

\begin{tabular}{lcccccccc}
\hline Depth $(\mathrm{km})$ & $0-15$ & $15-40$ & 50 & 100 & 150 & 200 & 250 & 300 \\
\hline Density $\left(\mathrm{g} \mathrm{cm}^{-3}\right)$ & 2.7 & 2.94 & 3.357 & 3.384 & 3.419 & 3.457 & 3.510 & 3.560 \\
\hline
\end{tabular}
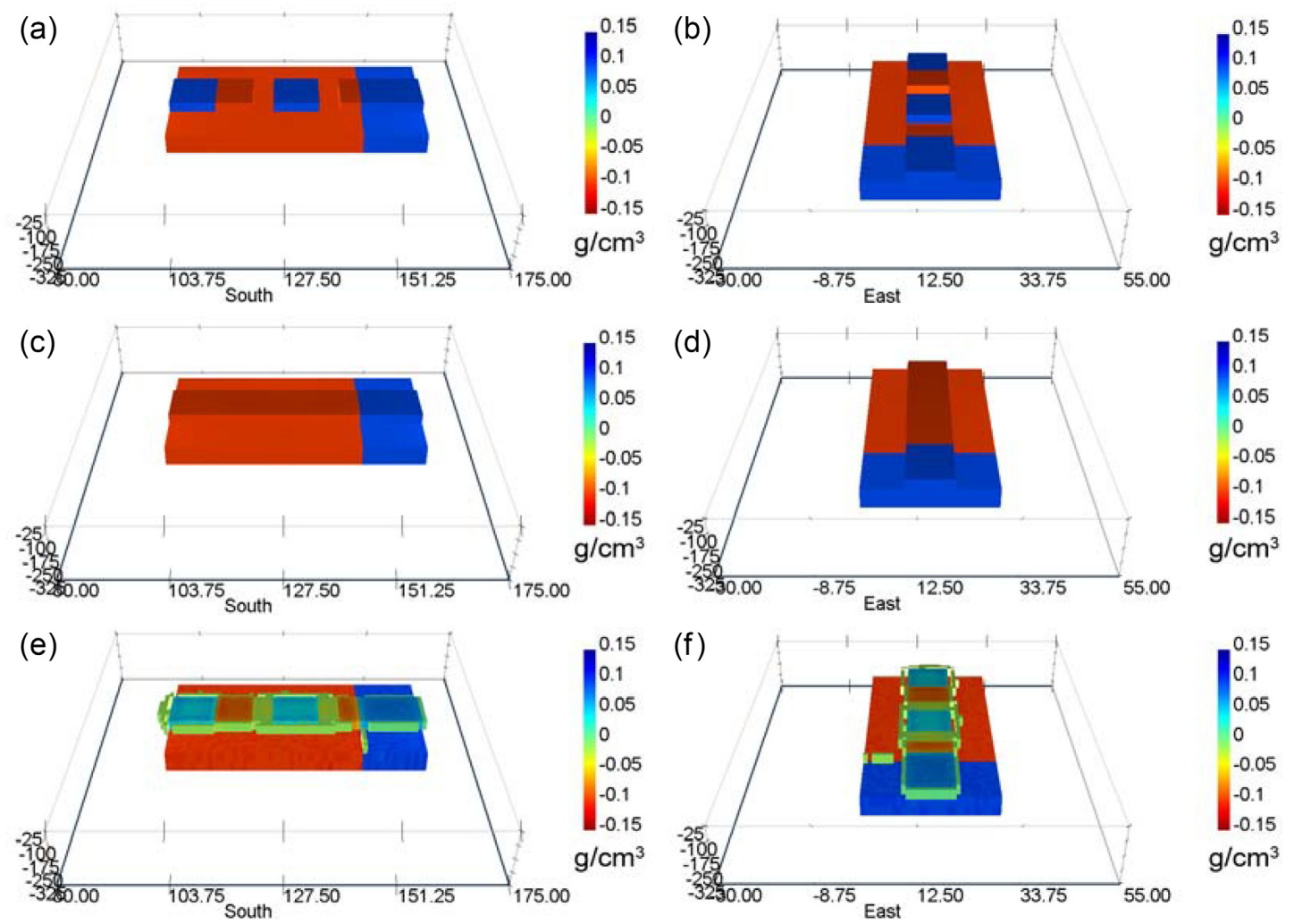

Figure 2. 3-D perspective views of synthetic model ( $a$ and b), initial model (c and d) and final model (e and f). Models are shown in a view from south to north ( $a, c$ and $\mathrm{e}$ ) and in a view from east to west (b, $\mathrm{d}$ and $\mathrm{f}$ ). The difference between the synthetic model and the initial model is the top-layer setting. The absolute density values, $|\rho|$, which are smaller than $0.005 \mathrm{~g} \mathrm{~cm}^{-3}$, are cut off in all models.
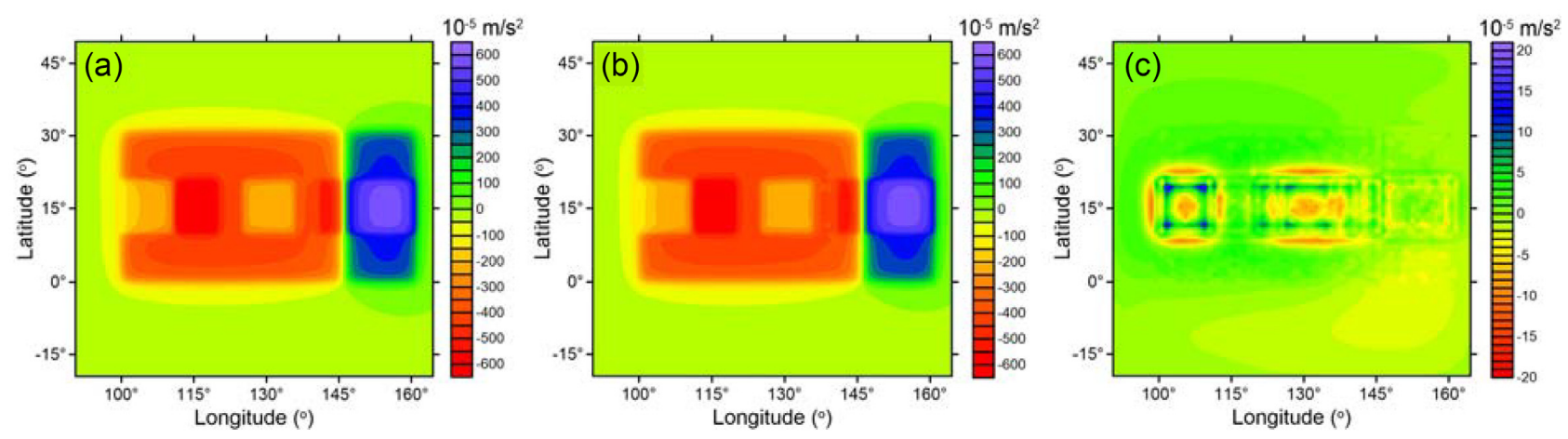

Figure 3. Theoretical gravity anomaly (a) of synthetic model (Figs 2a and b), inverted gravity anomaly (b) of constrained model (Figs 2 e and f) and data misfit (c).

et al. (2016), which were computed globally in the uppermost mantle up to a depth of $325 \mathrm{~km}$ by using the approach of Stixrude \& Lithgow-Bertelloni (2005); therefore, we refer to the above paper for a detailed description. The initial density variations at the depths of 50, 100, 150, 200, 250 and $300 \mathrm{~km}$ are shown in Fig. 6.

\subsection{Relation between the calculated density variations and seismic velocities}

The conversion factor is a relation between the $S$-wave velocity anomalies and computed density variations. It can be used to quantify thermal and compositional effects in the lithosphere (Root et 

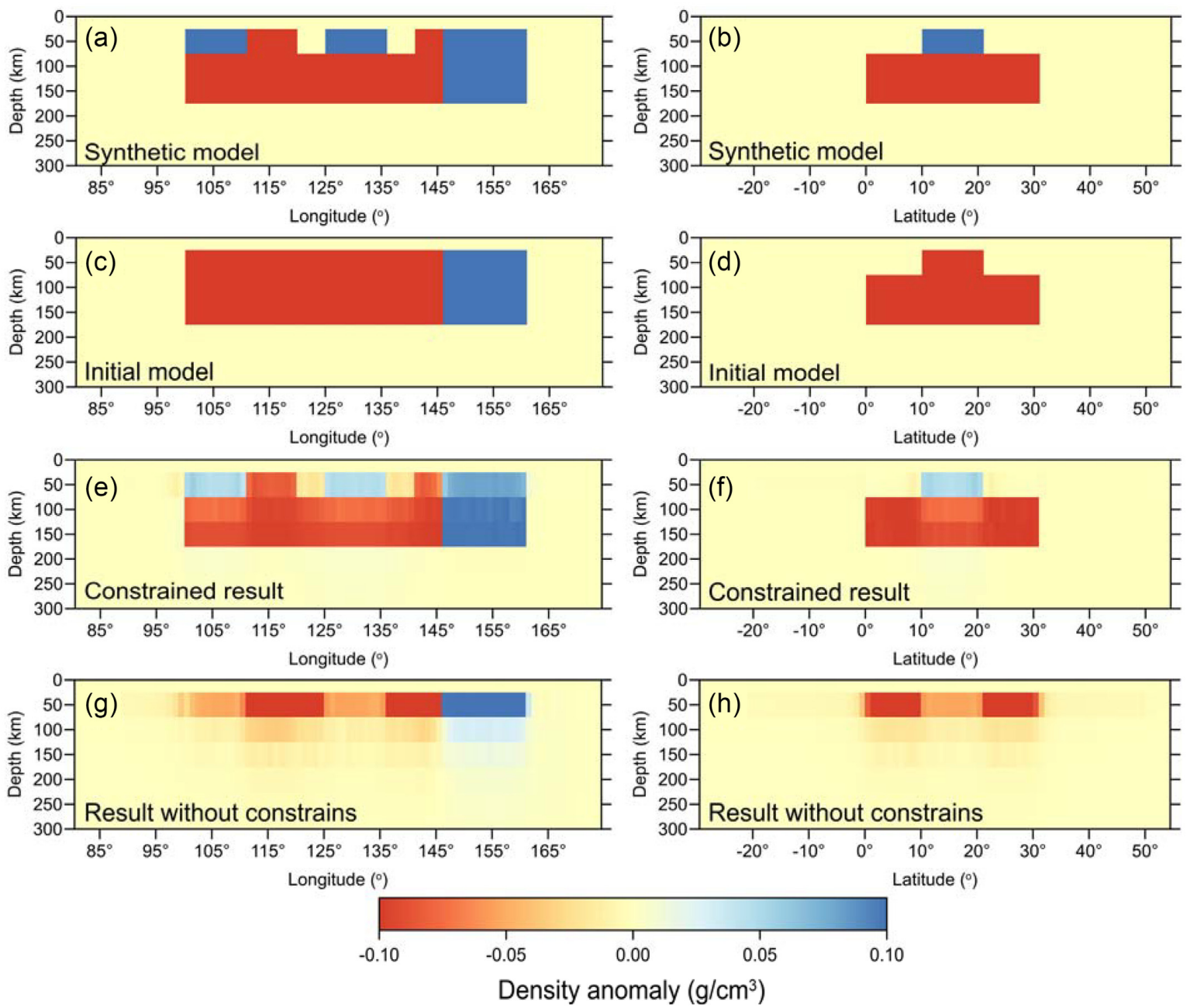

Figure 4. Comparisons of synthetic model ( $a$ and b), initial model ( $c$ and d), inverted model with constrains (e and $f$ ) and inverted model without constrains ( $g$ and $\mathrm{h}$ ) along profiles of $15.5^{\circ}$ latitude line ( $\mathrm{a}, \mathrm{c}, \mathrm{e}$ and $\mathrm{g}$ ) and $130.5^{\circ}$ longitude line $(\mathrm{b}, \mathrm{d}, \mathrm{f}$ and $\mathrm{h}$ ).

al. 2017). The conversion factor is given as follows:

$p=(\mathrm{d} \rho / \rho) /(\mathrm{dVs} / \mathrm{Vs})$,

where $\mathrm{d} \rho$ is the inverted density anomaly in this study, $\rho$ is the reference density value (Table 1 ) and the ratio of $\mathrm{d} V s / V_{S}$ is the $S$-wave velocity perturbation (Fig. 5) from the global tomography model SL2013sv (Schaeffer \& Lebedev 2013).

The inverted density variations in the upper mantle are affected by both thermal and compositional anomalies. In contrast, the velocity anomalies more relate to temperature variations (e.g. Stixrude \& Lithgow-Bertelloni 2005). To quantify these effects, we employ the density-velocity conversion factor. The positive conversion factor means the density anomaly is dominated by thermal effects, whereas the negative one indicates that the density anomaly is likely related to compositional variations. The calculated 3-D model of the conversion factor is to be compared with the tectonic fragmentation of the Philippine Sea and surrounding areas.

\section{INVERSION RESULTS}

The inverted density model produces gravity anomalies, which are very close to the mantle field with the misfit $\pm 2.7 \times 10^{-5} \mathrm{~m} \mathrm{~s}^{-2}$ (Fig. 7). The major differences between the inverted model and initial models are due to the variations of the mantle gravity anomalies. For instance, the initial model derived from the tomography model shows a low density anomaly beneath the Philippine Sea, while the mantle gravity shows positive anomaly. Therefore, our method provides a possibility to resolve additional features of the upper-mantle structure, which are not visible in seismic models due to a lack of resolution or low sensitivity of the wave speed to compositional changes. The obtained density variations characterize lateral variations of composition and temperature in the upper mantle. The inverted density model shows distinct differences of the upper mantle between the PSP and surrounding regions (Fig. 8). Higher density dominates in the upper mantle under the PSP at a depth of $50 \mathrm{~km}$ (Fig. 8). It is similar to the density distribution in the neighbouring PP and AP, but differs from those of the EP and the Sunda Plate (SP) at this depth. The two-layer density structure in the top of the mantle is typical for the lithosphere of the Philippine Sea. The low-density zone occupies a large region beneath the PSP, the SP, the Yangzte craton area and the southern Amur Plate at a depth of $100 \mathrm{~km}$ (Fig. 8). This low-density zone thickens eastwards and extends under the PP downwards to a depth of $\sim 150 \mathrm{~km}$ (Fig. 8, $150 \mathrm{~km}$ ). In the deeper mantle, the mantle density under the PSP increases at the depths of 200-300 km and becomes similar to those at the same depths under the EP including the Sunda tectonic area (Fig. 8, 200-300 km). Oppositely, the 

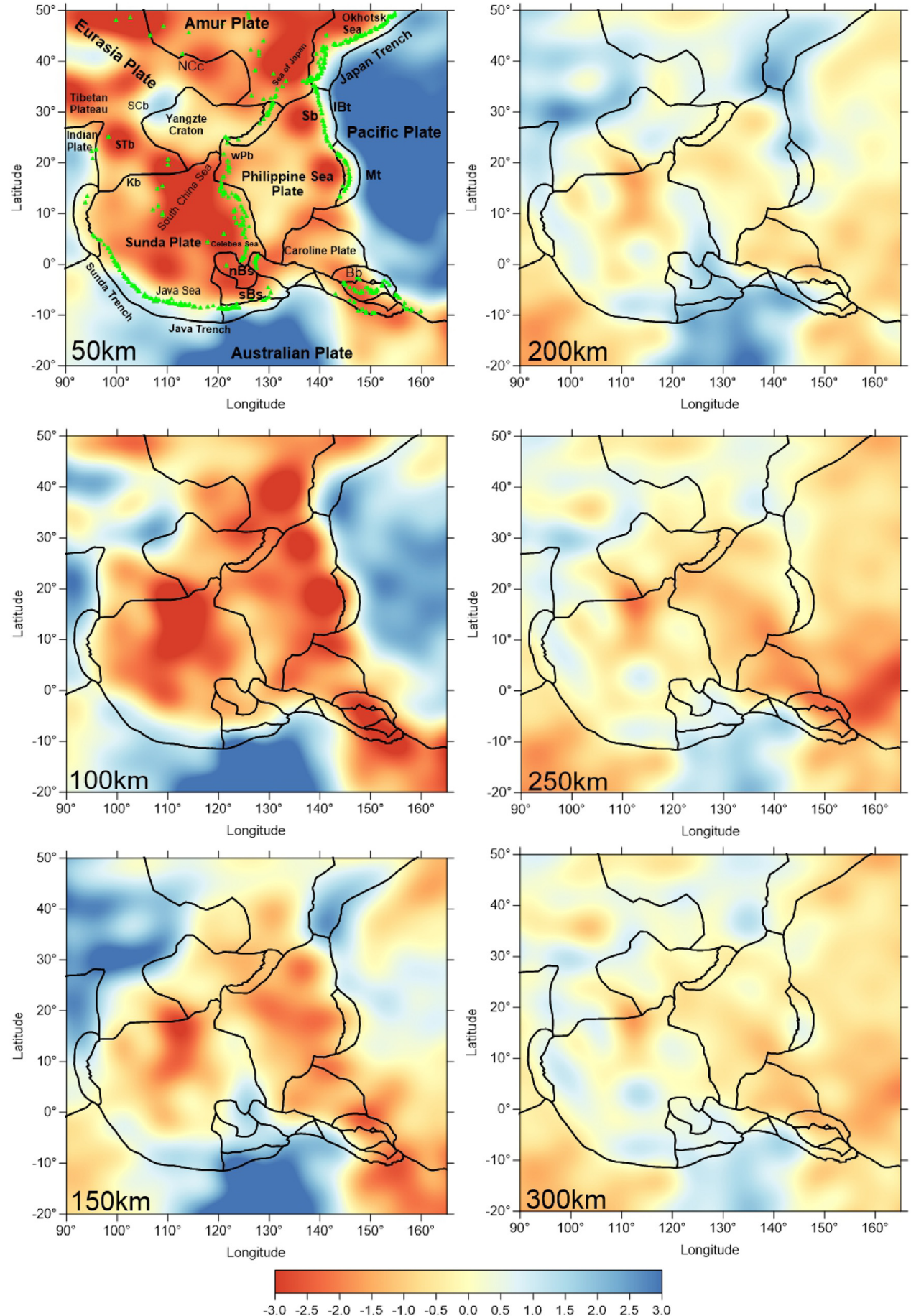

S-wave velocity perturbation (\%)

Figure 5. $S$-wave velocity perturbations of the tomography model SL2013sv of Schaeffer \& Lebedev (2013) at the depths 50, 100, 150, 200, 250 and 300 km. Green triangles show volcanoes as in Fig. 1(a).

low-density anomaly chiefly occupies this depth range in the PP and the AP. The thick low-density layer appears beneath the lithosphere in the study region, which may be explained by differences in composition and temperature relative to the overlying high-density layers (Fig. 10). The inverted density structure evidences that the relatively less dense and likely hotter material is located below the lithosphere in the collision zones dividing the lithospheric plates
(PSP, SP, EP, PP and AP). It should be noted that these density anomalies are estimated relative to the above-mentioned 1-D model (Table 1), which implies increase of density with depth. Therefore, a low-density anomaly at some depth does not necessarily indicate the inverse density-depth gradient; the absolute density may still increase with depth depending on the amplitude of the anomaly. 

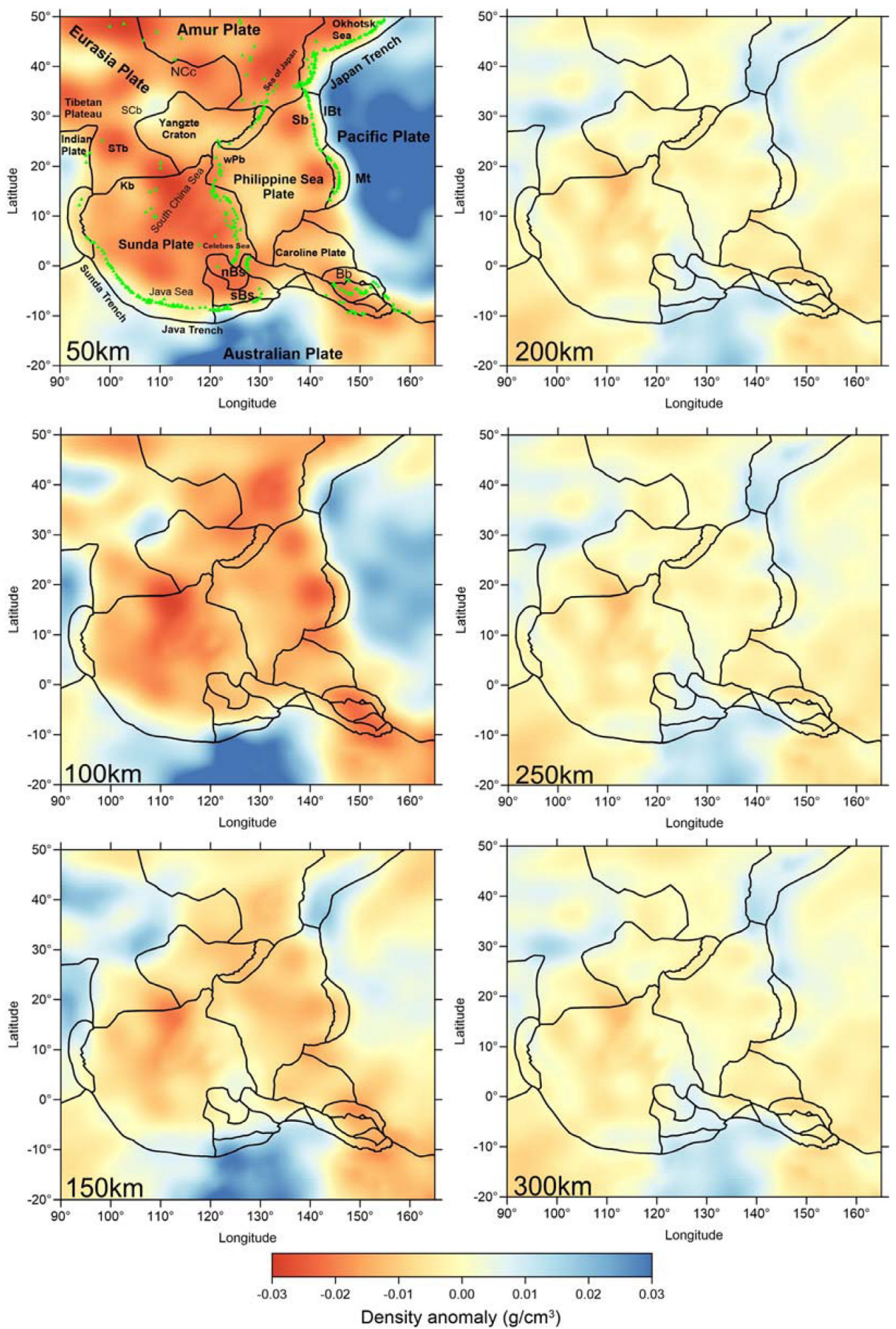

Figure 6. The initial density model at the depths 50, 100, 150, 200, 250 and $300 \mathrm{~km}$. Black lines represent plate boundaries. Green triangles show volcanoes as in Fig. 1(a).

\section{DISCUSSION}

\subsection{The Philippine Sea Plate}

As visible in vertical slices in the inverted density model (Fig. 9), the density structure of the upper mantle in the Philippine Sea is characterized by a three-layer pattern, which is significantly different from the westward PP and the eastward EP (Fig. 9b). The high-density layer in the upper mantle can be found beneath the
Philippine Sea at a depth of $\sim 75 \mathrm{~km}$, which overlays the anomalous low-density zone. This feature is responsible for the positive mantle gravity anomaly in the Philippine Sea (Fig. 1b). The boundary between them agrees well with the lithospheric bottom defined by the Litho1.0 model (Pasyanos et al. 2014) in the PSP region. The relatively thick low-density layer extends to a depth of about $175 \mathrm{~km}$ (Fig. 9c). Thickness of the top high-density layer is different in the western and eastern parts of the PSP. The thicker part located in 


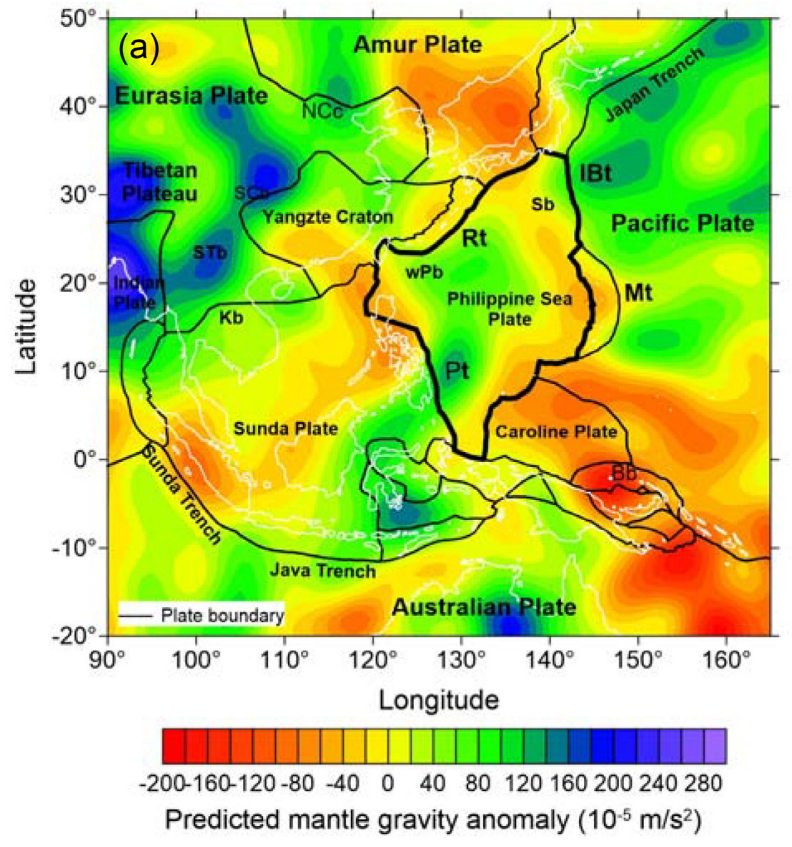

Figure 7. Predicted mantle gravity anomaly (a) and the data misfit (b).

the west Philippine Sea implies that the oceanic lithosphere of the west Philippine Basin is older and denser, and became mature after the seafloor spreading ended 30-33 Ma (Deschamps \& Lallemand 2002). In contrast, in the east Philippine Sea the younger oceanic lithosphere beneath the Parece Vela/Shikoku Basin is characterized by a rather thin high-density layer. It is consistent with a continuation of seafloor spreading after $30 \mathrm{Ma}$ (Mrozowski \& Hayes 1979).

Under the east PSP, anomalously high density at the bottom of the inverted model may relate to the stagnated slab of the PP beneath the Izu-Bonin trench and Shikoku Basin (Figs 9c and d). However, there is no evidence for a stagnated slab in the deep zone under the Mariana trench and Parece Vela Basin (Figs 9a and b). Zhao et al (2017) suggested that the partially subducted PP is teared eastwards from the northern IBM trench chain. Other studies proposed a similar interpretation (e.g. Miller et al. 2004; Ye et al. 2016). This zone is considered as a steep-angle subduction, and a corresponding part of the subducted slab might be broken. In this case, the gap behind the detached part of the lithospheric slab should represent a wide channel filled with upwelling magma from decompression melting in the asthenosphere. Upwelling mantle can heat and melt the lower lithosphere material, which replaces the cold lithosphere of the PSP.

At the Ryukyu trench, the northward subduction of the PSP has been defined by many tomography studies (e.g. Huang \& Zhao 2006; Isse et al. 2009; Li \& Van der Hilst 2010; Wei et al. 2015); however, such a subduction zone is not clearly visible in the inverted density model (Figs 9a and e). The reason could be insufficient resolution of the tomography model, although we observed a negative gravity anomaly located in the west of the Ryukyu trench (see in Fig. 1b). On the western margins of the PSP, there are some indications of subduction of the PSP under the Philippine Mobile Belt (Galgana et al. 2007) at the Philippine and East Luzon trenches (Figs 9c and d).

The thick low-density zone in the PSP is likely related to the sea-floor spreading in the Philippine Sea during last $50 \mathrm{Ma}$. In this case, the accumulated low-dense material beneath this structure is

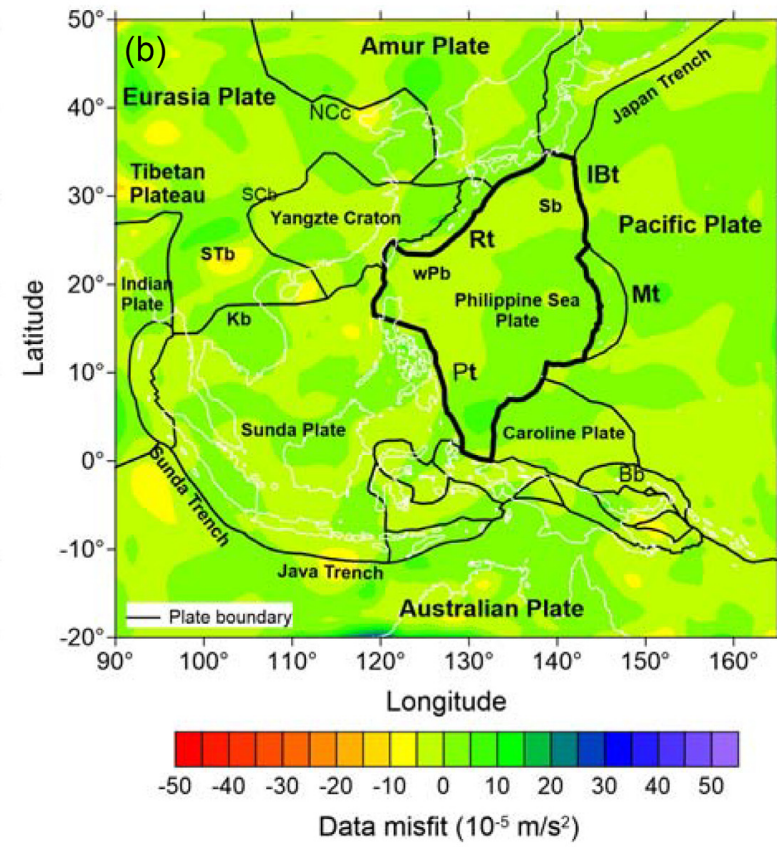

a result of the asthenosphere upwelling through the channel caused by the delaminated slab.

\subsection{Adjacent plates}

The density structure of the western PP is significantly differs from the PSP (Figs 9a-c). The $\sim 100-k m$-thick high-density layer lies on the thick and relatively low-dense asthenosphere which is typical for the old oceanic lithosphere. This density structure is in agreement with previous seismic tomography results. Between 100 and $150 \mathrm{~km}$ depth (Fig. 8), the low-density anomaly distributes through the region under the PSP and eastern EP. This might indicate that the underlying low-density zone extends across the Ryukyu trench (Fig. 8, at depths of 100 and $150 \mathrm{~km}$ ), although the Ryukyu trench is considered as the margin for both plates.

The SP is located southwest of the PSP. It was traditionally considered as a part of the EP but it is possibly separated from the EP and PSP since the Tertiary according to recent investigations (Bird 2003). Unlike the PSP, the SP has an upper-mantle density structure characterized by a two-layer pattern, in which a thick low-density layer overlies a high-density zone (Fig. 9c). However, the obtained density structure of the subcrustal layer may be biased by uncertainties of the crustal model used for computation of the residual gravity anomalies. The high-density zone is connected to the PSP and EP at the depths $150-200 \mathrm{~km}$, as well as with the subducted slabs of the Australian and Indian plates.

The AP is not connected directly to the PSP. However, the northward subduction zone of the plate may affect the density variation of the lithosphere and asthenosphere beneath the PSP. The inverted density model outlines shapes of the subduction zones along the Sunda-Java trench (Figs 9d and e). A large high-density block in the Banda Sea area is clearly observed at a depth of $100 \mathrm{~km}$ (Fig. 8). This block might be a remnant of the subducted slab from the Australia Plate. It is connected to the asthenosphere of the southern PSP below $200 \mathrm{~km}$. 

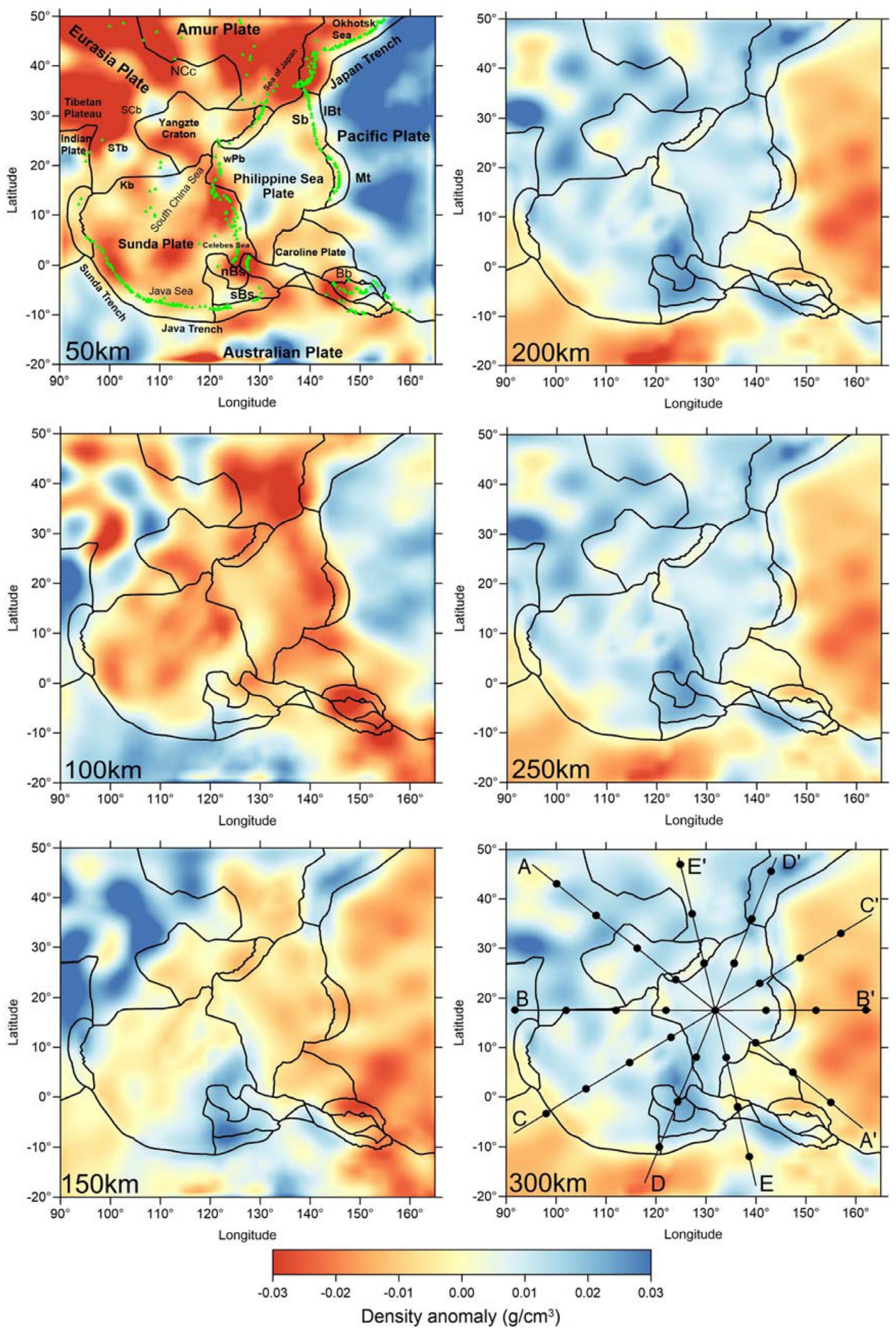

Figure 8. Inverted density variations at the depths 50, 100, 150, 200, 250 and $300 \mathrm{~km}$. Black lines represent plate boundaries. Green triangles show locations of volcanoes. Five profiles $\left(\mathrm{AA}^{\prime}, \mathrm{BB}^{\prime}, \mathrm{CC}^{\prime}, \mathrm{DD}^{\prime}\right.$ and $\left.\mathrm{EE}^{\prime}\right)$ at the $300 \mathrm{~km}$ plot show locations of vertical cross-sections in Fig. 9. The black dots represent the relative distance of each profile in Fig. 9.

For a broader region, a layer of low-density anomalies along $100 \mathrm{~km}$ depth (Fig. 8) beneath the SP, Amur Plate and PP is related to the low-velocity perturbations (Supporting Information Fig. S1), indicating that the thermal effect is the primary domination in density variations. The high-density materials dominate in a large area including the PSP, eastern EP, Amur and Sunda plates below the $200 \mathrm{~km}$ depth (Fig. 8). The similarity in the density structure likely suggests some relevance in their tectonic evolution.

\subsection{Density-velocity conversion factor and its relation to tectonics}

In order to investigate different factors affecting the density structure and their relation to tectonics, we estimated the density-velocity conversion factor for the study area (Fig. 10). The pronounced negative conversion factor appears in the PSP region the depths $50 \mathrm{~km}$ and below $200 \mathrm{~km}$, indicating that the density anomalies 

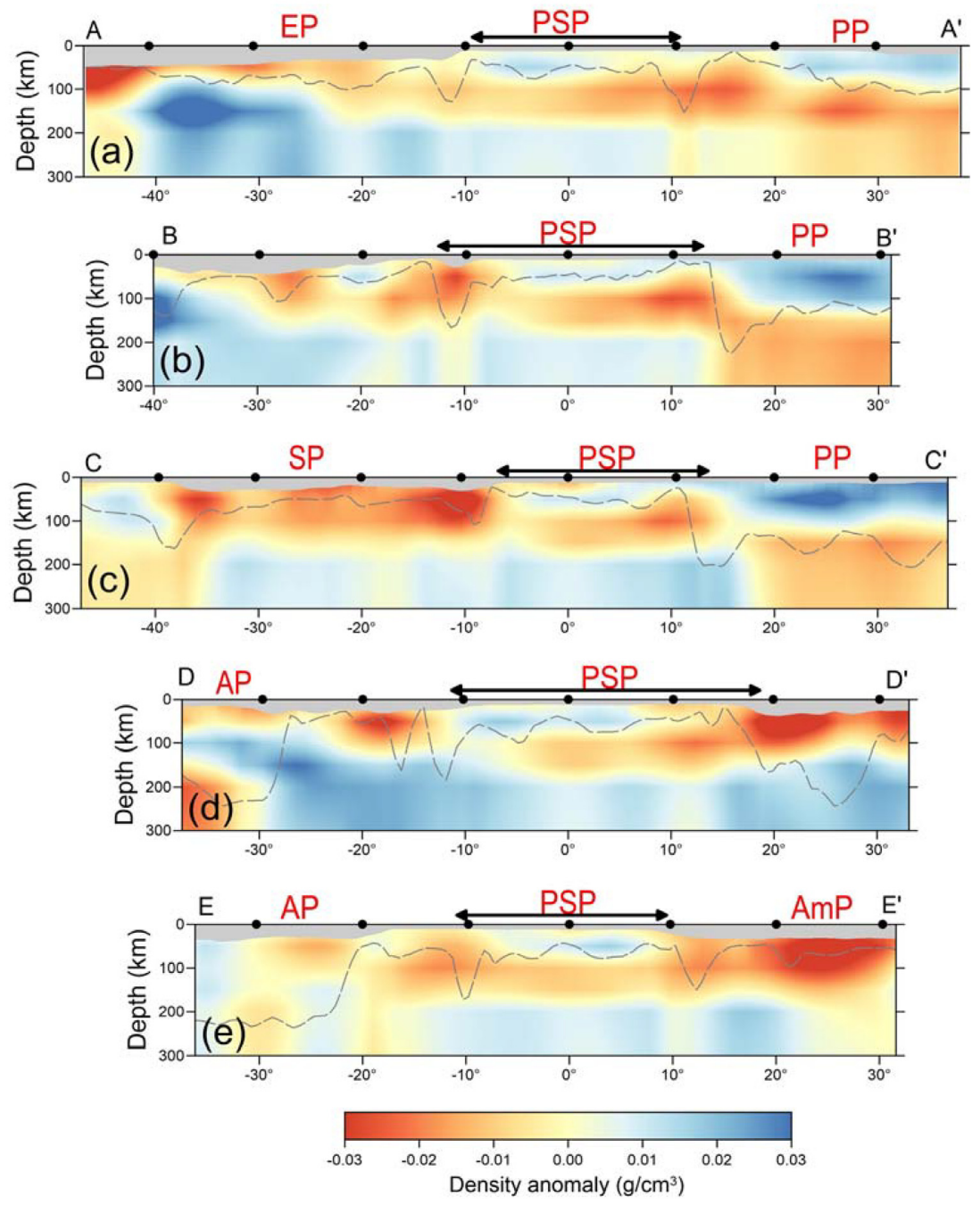

Figure 9. Vertical profiles of the inverted density structure along five lines, (a) $\mathrm{AA}^{\prime}$, (b) $\mathrm{BB}^{\prime}$, (c) $\mathrm{CC}^{\prime}$, (d) $\mathrm{DD}^{\prime}$ and (e) EE', shown in Fig. 6. Horizontal distance is a great circle distance in degrees with the centre point located at the cross-section. The black dots represent the locations and the distance of each profile in Fig. 8 (300 km). The lithosphere-asthenosphere boundary (LAB) from the LITHO1.0 model (Pasyanos et al. 2014) is delineated by grey dashed lines in the profiles. The main tectonic plates are labelled as: AP, Australian Plate; AmP, Amur Plate; EP, Eurasian Plate; PP, Pacific Plate; PSP, Philippine Sea Plate; SP, Sunda Plate. The black lines show the parts of the profiles crossing PSP.

in the uppermost and lower layers in the upper mantle are likely dominated by compositional effects. Other areas with the negative factor are located along the subduction zones at the plate margins, such as the Japan, Philippine and Sunda-Java trenches. Furthermore, these features deeper extend along with the subducting slabs.

The lateral and radial variations of the conversion factor indicate that the upper-mantle structure beneath the PSP is different from the adjacent regions. The depth changes of the conversion factor (negative values at 200-300 km, Fig. 10) might be related to the compositional anomaly associated with the dense mantle materials beneath the PSP. This anomalous and likely compositional effect is also found in the South China Sea area. These structures are very different compared to the continental lithosphere of EP and the oceanic lithosphere of PP.

\section{CONCLUSIONS}

We present a 3-D model of the upper-mantle density structure derived from a constrained inversion of the mantle gravity anomaly in spherical coordinates. The obtained results demonstrate principal features of the tectonic evolution of the PSP and the adjacent region. Resolution of the density model was improved in the inversion compared to the initial model based on seismic tomography in the Philippine Sea. We found that the high-density lithosphere is located in the oldest region of the west Philippine Sea. In contrast, the eastern part of PSP is characterized by the low-density anomaly associating with the young lithosphere. These features were not presented in the tomography model.

The uppermost mantle beneath the west Philippine Sea represents the thin, dense and cold lithosphere, which corresponds to the oldest part of the PSP. A thick, soft and relatively low-dense layer is found underneath the thin lithosphere. This layer is referred to the asthenosphere, which extends to the west and to the north and is consistent with the Sunda and south Amur plates at a depth of $100 \mathrm{~km}$. A transition zone from negative to positive density anomalies was found at a depth of $150 \mathrm{~km}$ underlying the PSP and the SP. The subducted PP and Indian-Australia Plate may play an important role in the density transition due to the interaction with the asthenosphere. The inverted density model also shows the deeper high-density zone at the depths 

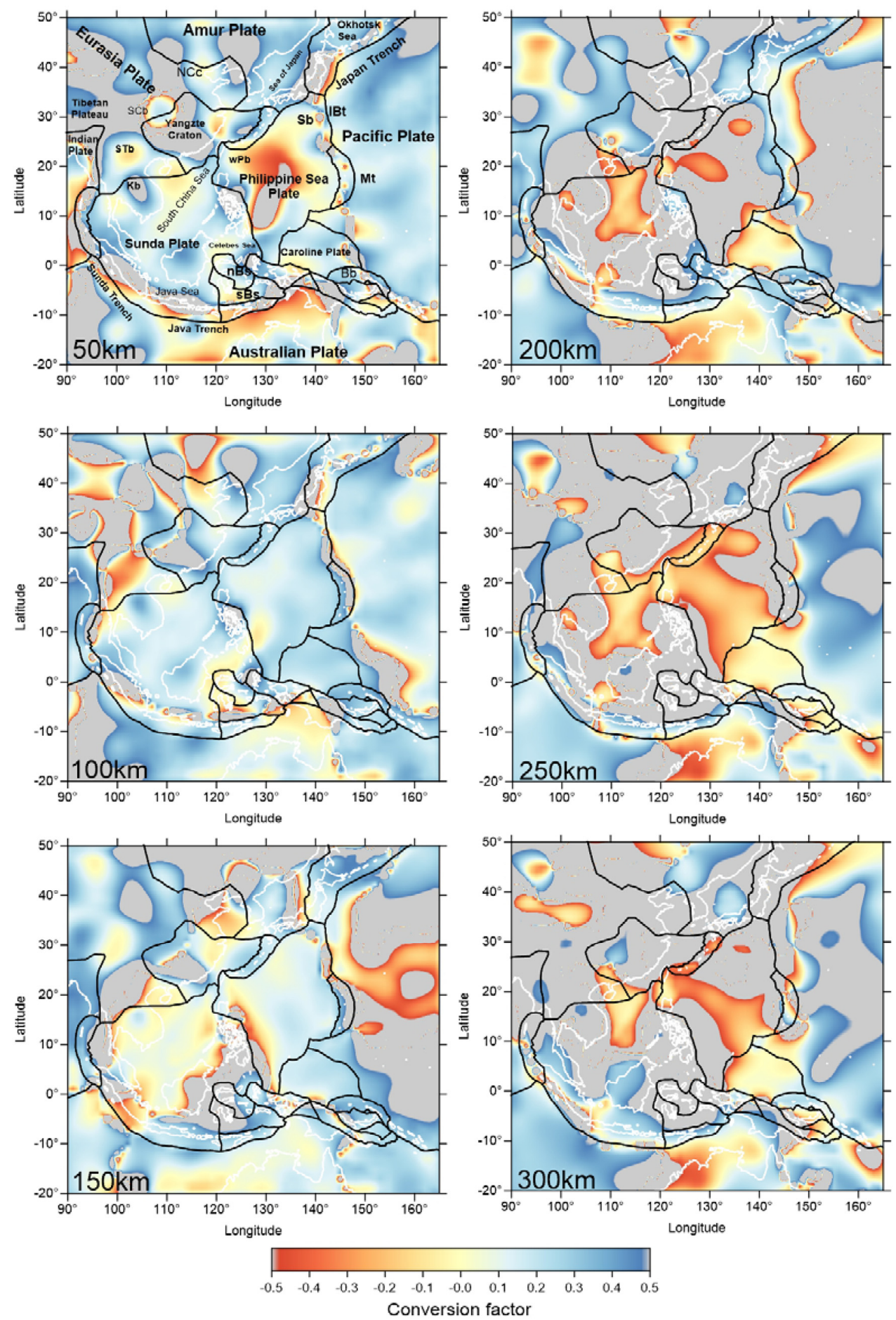

Figure 10. The lateral distribution of the conversion factor between the $S$-wave velocity perturbations (SL2013sv) and our final density anomalies at the depths $50-300 \mathrm{~km}$. The grey regions show locations with the conversion factor exceeding \pm 0.5 .

200-300 km under the Philippine Sea, which extends into the SP, the EP and the Amur Plate. This demonstrates a notable similarity in their density structure. We further located compositional changes affecting the density model by estimating the density-velocity conversion factor. We describe the layered structure in the PSP as a 'sandwich' pattern, which is unique and differs from the uppermost mantle structure of the adjacent region.

\section{ACKNOWLEDGEMENTS}

We are grateful to Shida Sun (Huazhong University of Science and Technology), Jinsong Du (China University of Geosciences, Wuhan) and Walter Mooney (USGS) for their valuable advices. We thank Editor, Prof. Bert Vermeersen for the constructive comments. We are grateful to Barend Root, Carlos Chaves and one 
anonymous reviewer for their comments, suggestions and recommendations. This study is supported by the National Natural Science Foundation of China (Grant Nos. 41574070 and 41104048). QL is supported by the National Science and Technology Major Project (2017ZX05008001-003). The data are contained in a published source (not a repository) cited in the References.

\section{REFERENCES}

Anderson, D.L. \& Bass, J.D., 1984. Mineralogy and composition of the upper mantle, Geophys. Res. Lett., 11(7), 637-640.

Bird, P., 2003. An updated digital model of plate boundaries, Geochem. Geophys. Geosyst., 4(3), 1027.

Brandmayr, E., Marson, I., Romanelli, F. \& Panza, G.F., 2011. Lithosphere density model in Italy: no hint for slab pull, Terra Nova, 23(5), 292-299.

Chaves, C.A.M. \& Ussami, N., 2013. Modeling 3-D density distribution in the mantle from inversion of geoid anomalies: application to the Yellowstone Province, J. geophys. Res., 118, 6328-6351.

Deschamps, A. \& Lallemand, S., 2002. The West Philippine Basin: an Eocene to early Oligocene back arc basin opened between two opposed subduction zones, J. geophys. Res., 107(B12), EPM 1-1-EPM 1-24.

Förste, C., Bruinsma, S., Abrikosov, O., Flechtner, F., Marty, J.C., Lemoine, J.M. \& Biancale, R., 2014. EIGEN-6C4-The latest combined global gravity field model including GOCE data up to degree and order 1949 of GFZ Potsdam and GRGS Toulouse, in EGU General Assembly Conference Abstracts, Vol. 16, pp. 3707, EGU Vienna.

Galgana, G.A., Hamburger, M.W., McCaffrey, R., Bacolcol, T.C. \& Aurelio, M.A., 2007. Modeling the Philippine Mobile Belt: tectonic blocks in a deforming plate boundary zone, in American Geophysical Union Fall Meeting abstract, G21C-0670, San Francisco.

Hall, R. \& Spakman, W., 2015. Mantle structure and tectonic history of SE Asia, Tectonophysics, 658, 14-45.

Hayes, G.P., Wald, D.J. \& Johnson, R.L., 2012. Slab1.0: a three-dimensional model of global subduction zone geometries, J. geophys. Res., 117, B01302.

Houseman, G.A. \& Molnar, P., 1997. Gravitational (Rayleigh-Taylor) instability of a layer with non-linear viscosity and convective thinning of continental lithosphere, Geophys. J. Int., 128(1), 125-150.

Huang, J. \& Zhao, D., 2006. High-resolution mantle tomography of China and surrounding regions, J. geophys. Res., 111(B9), 4813-4825.

Isse, T. et al., 2009. Seismic structure of the upper mantle beneath the Philippine Sea from seafloor and land observation: implications for mantle convection and magma genesis in the Izu-Bonin-Mariana subduction zone, Earth planet. Sci. Lett., 278(1-2), 107-119.

Kaban, M.K. \& Schwintzer, P., 2001. Oceanic upper mantle structure from experimental scaling of VS and density at different depths, Geophys. J. Int., 147(1), 199-214.

Kaban, M.K. \& Trubitsyn, V., 2012. Density structure of the mantle transition zone and the dynamic geoid, J. Geodyn., 59-60, 183-192.

Kaban, M.K., Schwintzer, P., Artemieva, I.M. \& Mooney, W.D., 2003. Density of the continental roots: compositional and thermal contributions, Earth planet. Sci. Lett., 209(1-2), 53-69.

Kaban, M.K., Petrunin, A.G., Schmeling, H. \& Shahraki, M., 2014a. Effect of decoupling of lithospheric plates on the observed geoid, Surv. Geophys., 35, 1361-1373.

Kaban, M.K., Tesauro, M., Mooney, W.D. \& Cloetingh, S.A.P.L., 2014b. Density, temperature, and composition of the North American lithosphere - new insights from a joint analysis of seismic, gravity, and mineral physics data: 1. Density structure of the crust and upper mantle, Geochem. Geophys. Geosyst., 15, 4781-4807.

Kaban, M.K., Stolk, W., Tesauro, M., Khrepy, S.E., Arifi, N.A., Beekman, F. \& Cloetingh, S.A.P.L., 2016.3D density model of the upper mantle of Asia based on inversion of gravity and seismic tomography data, Geochem. Geophys. Geosyst., 17, 4457-4477.

Kay, R.W. \& Kay, S.M., 1993. Delamination and delamination magmatism, Tectonophysics, 219(1-3), 177-189.
Li, C. \& van der Hilst, R.D., 2010. Structure of the upper mantle and transition zone beneath Southeast Asia from traveltime tomography, $J$. geophys. Res., 115, B7308.

Li, Y. \& Oldenburg, D.W., 1998. 3-D Inversion of gravity data, Geophysics, 63(1), 109-119.

Liang, Q., Chen, C. \& Li, Y., 2014. 3-D inversion of gravity data in spherical coordinates with application to the GRAIL data, J. geophys. Res., 119(6), 1359-1373.

Miller, M.S., Kennett, B.L.N. \& Lister, G.S., 2004. Imaging changes in morphology, geometry, and physical properties of the subducting Pacific plate along the Izu-Bonin-Mariana arc, Earth planet. Sci. Lett., 224(3-4), 363-370.

Mooney, W.D. \& Kaban, M.K., 2010. The North American upper mantle: density, composition, and evolution, J. geophys. Res., 115, B12424.

Mrozowski, C.L. \& Hayes, D.E., 1979. The evolution of the Parece Vela basin, eastern Philippine Sea, Earth planet. Sci. Lett., 46, 49-67.

Müller, R.D., Sdrolias, M., Gaina, C. \& Roest, W.R., 2008. Age, spreading rates and spreading symmetry of the world's ocean crust, Geochem. Geophys. Geosyst., 9, Q04006.

Niu, F., Kawakatsu, H. \& Fukao, Y., 2003. Seismic evidence for a chemical heterogeneity in the mid-mantle: a strong and slightly dipping seismic reflector beneath the Mariana subduction zone, J. geophys. Res., 108(B9), 2419.

Pasyanos, M.E., Masters, T.G., Laske, G. \& Ma, Z., 2014. LITHO1.0: an updated crust and lithospheric model of the Earth, J. geophys. Res., 119(3), 2153-2173.

Petrunin, A.G., Kaban, M.K., Rogozhina, I. \& Trubitsyn, V., 2013. Revising the spectral method as applied to modeling mantle dynamics, Geochem. Geophys. Geosyst., 14, 3691-3702.

Porritt, R.W., Miller, M.S., O’Driscoll, L.J., Harris, C.W., Roosmawati, N. \& Costa, L.T.D., 2016. Continent-arc collision in the Banda arc imaged by ambient noise tomography, Earth planet. Sci. Lett., 449, 246-258.

Ritsema , J., Deuss, A., van Heijst , H. J. \& Woodhouse , J. H., 2011. S40RTS: a degree-40 shear-velocity model for the mantle from new Rayleigh wave dispersion, teleseismic traveltime and normal-mode splitting function measurements, Geophys. J. Int., 184(3), 1223-1236.

Root, B.C., Ebbing, J., van der Wal, W., England, R.W. \& Vermeersen, L.L.A., 2017. Comparing gravity-based to seismic-derived lithosphere densities: a case study of the British Isles and surrounding areas, Geophys. J. Int., 208(3), 1796-1810.

Schaeffer, A.J. \& Lebedev, S., 2013. Global shear-speed structure of the upper mantle and transition zone, Geophys. J. Int., 194(1), 417-449.

Shito, A., Suetsugu, D. \& Furumura, T., 2015. Evolution of the oceanic lithosphere inferred from $\mathrm{Po} / \mathrm{So}$ waves traveling in the Philippine Sea Plate, J. geophys. Res., 120, 5238-5248.

Stixrude, L. \& Lithgow-Bertelloni, C., 2005. Thermodynamics of mantle minerals - I. Physical properties, Geophys. J. Int., 162(2), 610-632.

Stolk, W., Kaban, M.K., Beekman, F., Tesauro, M., Mooney, W.D. \& Cloetingh, S., 2013. High resolution regional crustal models from irregularly distributed data: application to Asia and adjacent areas, Tectonophysics, 602, 55-68.

Tang, Q. \& Zheng, C., 2013. Crust and upper mantle structure and its tectonic implications in the South China Sea and adjacent regions, J. Asian Earth Sci. 62, 510-525.

Tesauro, M., Kaban, M.K., Mooney, W.D. \& Cloetingh, S.A.P.L., 2014. Density, temperature, and composition of the North American lithospherenew insights from a joint analysis of seismic, gravity, and mineral physics data: 2. Thermal and compositional model of the upper mantle, Geochem. Geophys. Geosyst., 15, 4808-4830.

Wang, H. \& Currie, C.A., 2015. Magmatic expressions of continental lithosphere removal, J. geophys. Res., 120, 7239-7260.

Wei, W., Zhao, D., Xu, J., Wei, F. \& Liu, G., 2015. $P$ and $S$ wave tomography and anisotropy in Northwest Pacific and East Asia: Constraints on stagnant slab and intraplate volcanism, J. geophys. Res. , 120, 1642-1666.

Wu, J., Suppe, J., Lu, R. \& Kanda, R., 2016. Philippine Sea and East Asian plate tectonics since 52 Ma constrained by new subducted slab reconstruction methods, J. geophys. Res., 121(6), 4670-4741. 
Ye, L., Lay, T., Zhan, Z., Kanamori, H. \& Hao, J., 2016. The isolated $\sim 680 \mathrm{~km}$ deep 30 May $2015 \mathrm{Mw} 7.9$ Ogasawara (Bonin) Islands earthquake, Earth Planet. Sci. Lett., 433, 169-179.

Yu, C., Shi, X., Yang, X., Zhao, J., Chen, M. \& Tang, Q., 2017. Deep thermal structure of Southeast Asia constrained by S-velocity data, Mar. Geophys. Res., 38(4), 341-355.

Zhao, D., Fujisawa, M. \& Toyokuni, G., 2017. Tomography of the subducting Pacific slab and the 2015 Bonin deepest earthquake (Mw 7.9), Sci. Rep., 7, 44487.

\section{SUPPORTING INFORMATION}

Supplementary data are available at $G J I$ online.

Figure S1. Comparisons of the final density anomaly and $S$-wave velocity disturbances (Schaefer \& Lebedev 2013) at different depths of 50, 100, 150, 200, 250 and $300 \mathrm{~km}$ in the Philippine Sea and adjacent region.
Figure S2. Corrections to the initial density model obtained in the inversion for the PSP and adjacent regions. The corrections represent a difference between the inverted model (final) and the initial model.

Figure S3. Absolute densities (in unit of $\mathrm{g} \mathrm{cm}^{-3}$ ) at different depths of 50,100, 150, 200, 250 and $300 \mathrm{~km}$ in the Philippine Sea and adjacent region. The density values are calculated from the final density model and the 1-D reference model (see in Table 1).

Figure S4. L-curves of gravity inversions for the synthetic model (see in Fig. 2) without constraint (a) and with constraint (b). The dots and the numbers represent different regularization parameters and its values, respectively.

Please note: Oxford University Press is not responsible for the content or functionality of any supporting materials supplied by the authors. Any queries (other than missing material) should be directed to the corresponding author for the paper. 